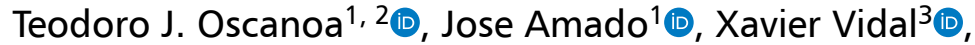
Andrea Savarino ${ }^{4}$ (D), Roman Romero-Ortuno ${ }^{5,6(0)}$

${ }^{1}$ Facultad de Medicina Humana, Universidad Nacional Mayor de San Marcos. Lima, Perú

${ }^{2}$ Facultad de Medicina Humana, Universidad de San Martín de Porres. Drug Safety Research Center, Hospital Almenara, ESSALUD, Lima, Perú

${ }^{3}$ Clinical Pharmacology Department, Vall d'Hebron Hospital, Barcelona, Spain

${ }^{4}$ Department of Infectious Diseases, Istituto Superiore di Sanità, Rome, Italy

${ }^{5}$ Discipline of Medical Gerontology, Mercer's Institute for Successful Ageing, St James's Hospital, Dublin, Ireland

${ }^{6}$ Global Brain Health Institute, Trinity College Dublin, Ireland

\title{
Metformin therapy, severity and mortality of SARS-CoV-2 infection: a meta-analysis
}

\section{ABSTRACT}

Background. It has been postulated that metformin could have anti-SARS-CoV-2 action. This raises the hypothesis that people who take metformin may have lower SARS-CoV-2 severity and/or mortality.

Objectives. To conduct a meta-analysis of the association between the use of Metformin and risk of severity and mortality in SARS-CoV-2 infection.

Methods. We searched PubMed, EMBASE, Google scholar, the Cochrane Database of Systematic Reviews and preprint servers (medRxiv and Research Square) for studies published between December 2019 and January 2021. Data was extracted on study location, year of publication, design, number of participants, sex, age at baseline, body mass index, and exposure and outcome definition. Effect statistics were pooled using random effects models with $95 \%$ confidence intervals (CI). The quality of included studies was assessed with the Newcastle-Ottawa Scale (NOS).

Results. Thirty-two observational studies were included, combining to a total sample of $\mathbf{4 4 3 0 6}$ participants. The mean NOS score of included studies was 7.9. Results suggested that metformin use was associated with a reduced risk of SARS-CoV-2 mortality (OR $=0.56$,

Address for correspondence:

Teodoro J. Oscanoa

Universidad de San Martín de Porres

Facultad de Medicina Humana

Centro de Investigación de Seguridad de Medicamentos

Lima, Peru

e-mail: tjoscanoae@gmail.com; toscanoae@usmp.pe

Clinical Diabetology 2021, 10; 4: 317-329

DOI: $10.5603 /$ DK.a2021.0035

Received: 3.01.2021

Accepted: 8.03.2021
95\% Cl: $0.46-0.68, \mathrm{P}<0.001 ; 22$ studies) but not with disease severity $(\mathrm{OR}=0.85,95 \% \mathrm{Cl}: 0.71-1.02$, $P=0.077 ; 15$ studies). In the subgroup analysis, metformin reduces the risk of mortality $(\mathrm{OR}=0.69,95 \% \mathrm{Cl}$ : $0.55-0.88 ; \mathrm{P}=0.002)$ and severity $(\mathrm{OR}=0.83,95 \% \mathrm{Cl}$ : $0.70-0.97, P=0.023$ ) in patients aged 70 and above. Conclusions. The use of metformin was associated to lower risk of mortality from SARS-CoV-2 infection. This association does not imply causation and further research is required to clarify potential mechanisms. (Clin Diabetol 2021; 10; 4: 317-329)

Key words: SARS-CoV-2 infection, COVID-19, metformin, mortality, type 2 diabetes

\section{Introduction}

Metformin (dimethyl biguanide) roots from the medieval European herbal medicine (Galega officinalis, French lilac), rich in guanidine and was used in patients with influenza [1-3]. Metformin is a guanidine derivative synthesized in the 1920 s and approved by the FDA in 1994 and since 2009 is the first-line oral treatment for type 2 diabetes mellitus (T2DM) according to the ADA (American Diabetes Association) and EASD ( European Association for the Study of Diabetes) [4].

At the liver level, metformin inhibits the mitochondrial respiratory chain, activating AMP protein kinase (AMPK) and improving insulin sensitivity through effects on fat metabolism; additionally, it decreases CAMP, thus reducing the expression of gluconeogenic enzymes. Furthermore, metformin inhibits fructose-1,6bisphosphatase by a hepatic AMPK-independent mechanism [2]. 
SARS-CoV-2 uses angiotensin-converting enzyme 2 (ACE2) as a receptor to enter the human cell, through the interaction of its spike proteins (S1) with the N-terminal region of $A C E 2$. As part of the process, the RBD-PD complex is formed, made up of the receptor binding domain (RBD) of the virus bound to the PD (the protease domain) of the human ACE2 receptor [5]. It has been postulated that in the pathophysiology of the acute lung injury (ALI) caused by SARS-CoV-2, ACE2 is involved through autophagy linked to the AMPK/mTOR pathway [6]. In animal studies, AMPK has been shown to increase ACE2 expression and stability by phosphorylation of ACE2 [6].

It has been hypothesized that by acting on AMPK, metformin may reduce the inflow of SARS-CoV-2 to the cell and avoid downregulation of ACE2 receptors caused by the virus [7]. Previous studies in animal models have shown that metformin may have immunomodulatory, antiviral and preventive activity against acute lung injury $[8,9]$. In the context of the current COVID-19 pandemic, it is not known if humans with type 2 diabetes who use metformin may have protection against adverse outcomes from SARS-CoV-2 infection. Hence, the present systematic review investigated the association between previous use of Metformin in diabetic patients and mortality and severity from SARS-CoV-2 infection.

\section{Methods}

This study was conducted following the guidelines of the Preferred Reporting Items for Systematic Reviews and Meta-analyses (PRISMA) [10].

\section{Search strategy}

Two independent investigators performed a systematic review in PubMed, EMBASE, Google scholar, the Cochrane Database of Systematic Reviews and preprint servers (medRxiv and Research Square) for studies published between December 2019 and January 2021. The full search strategy can be seen in Appendix 1 .

\section{Eligibility criteria}

The inclusion criteria for the studies were: randomized controlled trials (RCTs) or observational studies reporting data on Metformin and risk of SARS-CoV-2 infection mortality and/or severity. We included studies in English (all ages) that presented data on hazard ratios (HRs), relative risks (RRs), or odds ratios (ORs) with confidence intervals ( $\mathrm{Cls}$ ) or offered enough data to allow those to be calculated.

\section{Quality assessment}

The quality of observational studies (cohort and case control studies) and RCTs were appraised accord- ing to the Newcastle-Ottawa Quality Assessment Scale (NOS) [11] and the Cochrane Risk of Bias Assessment Tool [12] respectively. Two investigators evaluated the quality of the studies independently. Conflicting results were resolved by discussion and involvement of a third reviewer if necessary.

\section{Data extraction}

The following data were extracted from each study: authors, study location, year of publication, study design, number of participants, sex, age at baseline, outcome definition, exposure definition, body mass index (BMI) and effect estimates and 95\% Cls.

\section{Statistical analyses}

\section{Statistical analyses}

Primary analyses evaluated the association (hazard ratios, relative risks or odds ratios) between metformin and risk of mortality in SARS-CoV-2 infection. We used the random effects model with an inverse variance method to calculate the pooled RRs and $95 \% \mathrm{Cls}$ according to the heterogeneity between studies [13]. In order to calculate the effect size of metformin and risk of severity of in SARS-CoV-2 infection, the relative risk or odds ratio published by the authors of the included studies were used. The overall estimates in the pooled analysis were obtained using Stata 13 software (Stata Corp LP, College Station, TX). Subgroups analyses were performed according to mean age and BMI.

\section{Results}

\section{Characteristics of included studies}

The flowchart of included studies is detailed in Figure 1. Out of 946 potentially relevant articles, and following application of inclusion criteria, 32 studies were retained including a total of 44306 participants. The included studies were conducted in Austria [14], Belgium [15], China [16-24], France [25-27], Hong Kong [28], Iraq [29], Italy [30, 31], Russia [32]which determines the high relevance of risk factor analysis for outcomes in DM patients to substantiate the strategy for this category of patients. AIM: To assess the effect of clinical and demographic parameters (age, gender, body mass index (BMI, South Korea [33, 34], Spain [35, 36], UK [37-41] and USA [42-45].

In terms of study design, 18 were case-control, 12 cohort, and 2 cross-sectional studies. Across studies, mean age was $66.7+5.3$ years and $54.8 \%$ were men. The mean BMI was $27.5+2.8$ (13 studies). The mean NOS score of included studies was 7.9 (range: 7-9). The full characteristics of included studies are detailed in Table 1. 


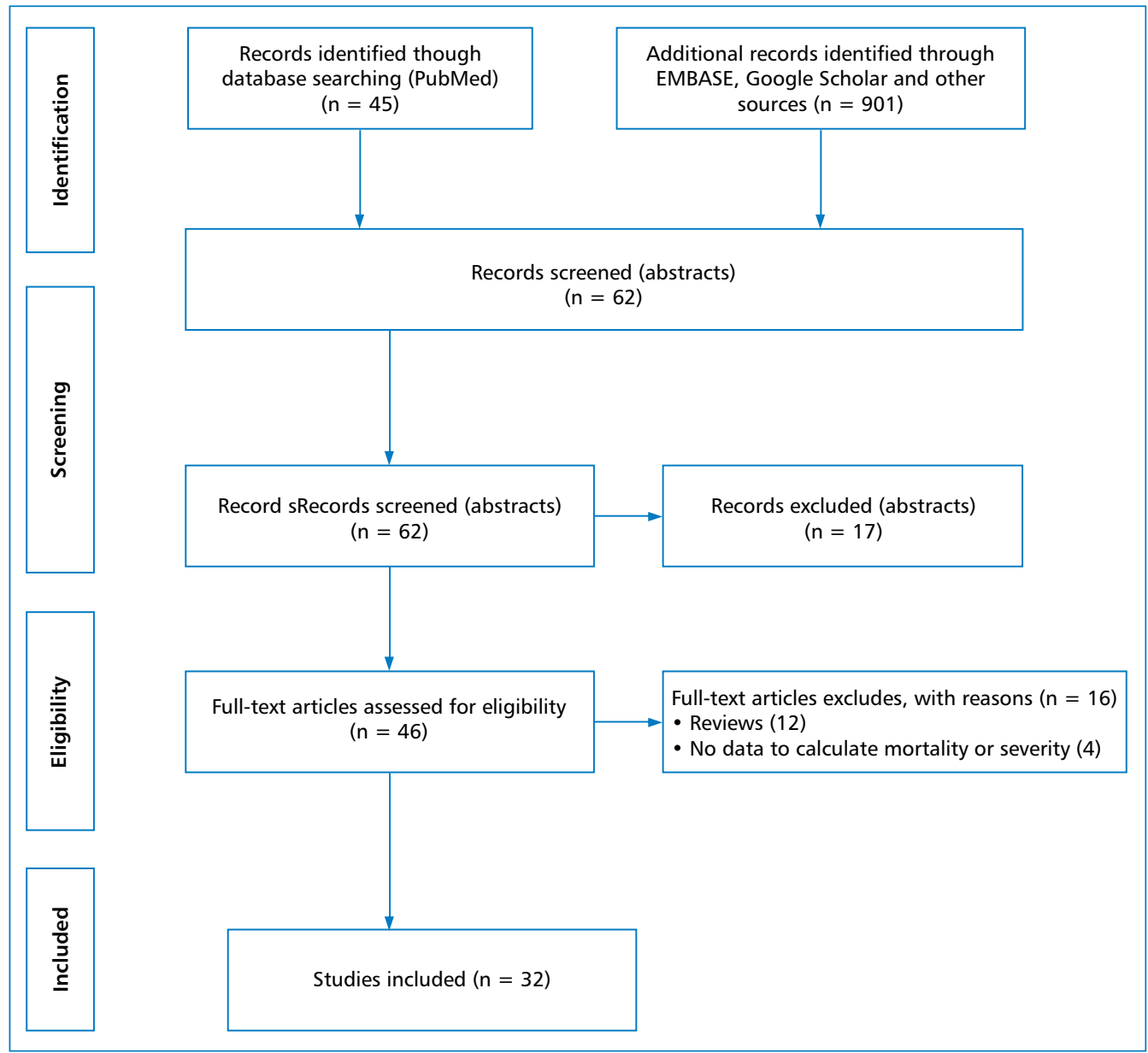

Figure 1. Study screening flowchart

\section{Metformin and risk of mortality} in SARS-CoV-2 infection

As shown in Figure 2, Metformin use was associated with reduced risk of mortality $(O R=0.56,95 \%$ $\mathrm{Cl}$ : 0.46-0.68, $\mathrm{P}<0.001 ; 22$ studies)

Metformin and risk of severe SARS-CoV-2 infection

The severity criteria of the included studies (15) were intensive care unit (ICU) admission (7 studies), acute respiratory distress syndrome (2), mechanical ventilation (3), and CT image / ICU admission / mechanical ventilation (3) (Table 1). And as shown in Figure 3, metformin was not significantly associated with disease severity $(\mathrm{OR}=0.85,95 \% \mathrm{Cl}$ : 0.71-1.02, $\mathrm{P}=0.077 ; 15$ studies).

Metformin and risk of mortality and severe (composite endpoint) SARS-CoV-2 infection

Three studies analyzed composite endpoint (mortality and severity) $[27,28,40]$ and metformin was not significantly associated with disease severity and mortality $(\mathrm{OR}=0.82,95 \% \mathrm{Cl}$ : 0.44-1.53, $P=0.025)$.

Age and BMI subanalyses

In the subgroup analysis, metformin reduces the risk of mortality $(\mathrm{OR}=0.69,95 \% \mathrm{Cl}: 0.55-0.88$; $\mathrm{P}=0.002)$ and severity $(\mathrm{OR}=0.83,95 \% \mathrm{Cl}: 0.70-0.97$, $\mathrm{P}=0.023$ ) in patients aged 70 and above. In studies with a predominance of male, metformin reduces the risk of mortality $(\mathrm{OR}=0.62,95 \% \mathrm{Cl}: 0.50-0.77$; $\mathrm{P}<0.001)$ and severity $(\mathrm{OR}=0.84,95 \% \mathrm{Cl}: 0.73-0.97$; $P=0.016)$. In the studies that reported BMI, apparently the decrease in mortality was greater in those with $\mathrm{BMI}>30$ compared to those with $\mathrm{BMI}<30$ (OR $=0.49,95 \% \mathrm{Cl}: 0.41-0.58$ vs. $\mathrm{OR}=0.30,95 \% \mathrm{Cl}$ : $0.17-0.54) ;$ there were no severity studies with $\mathrm{BMI}$ $>30$. The sub-analysis by sex was not done, because the studies did not report their results separately, except for one study [44]. 


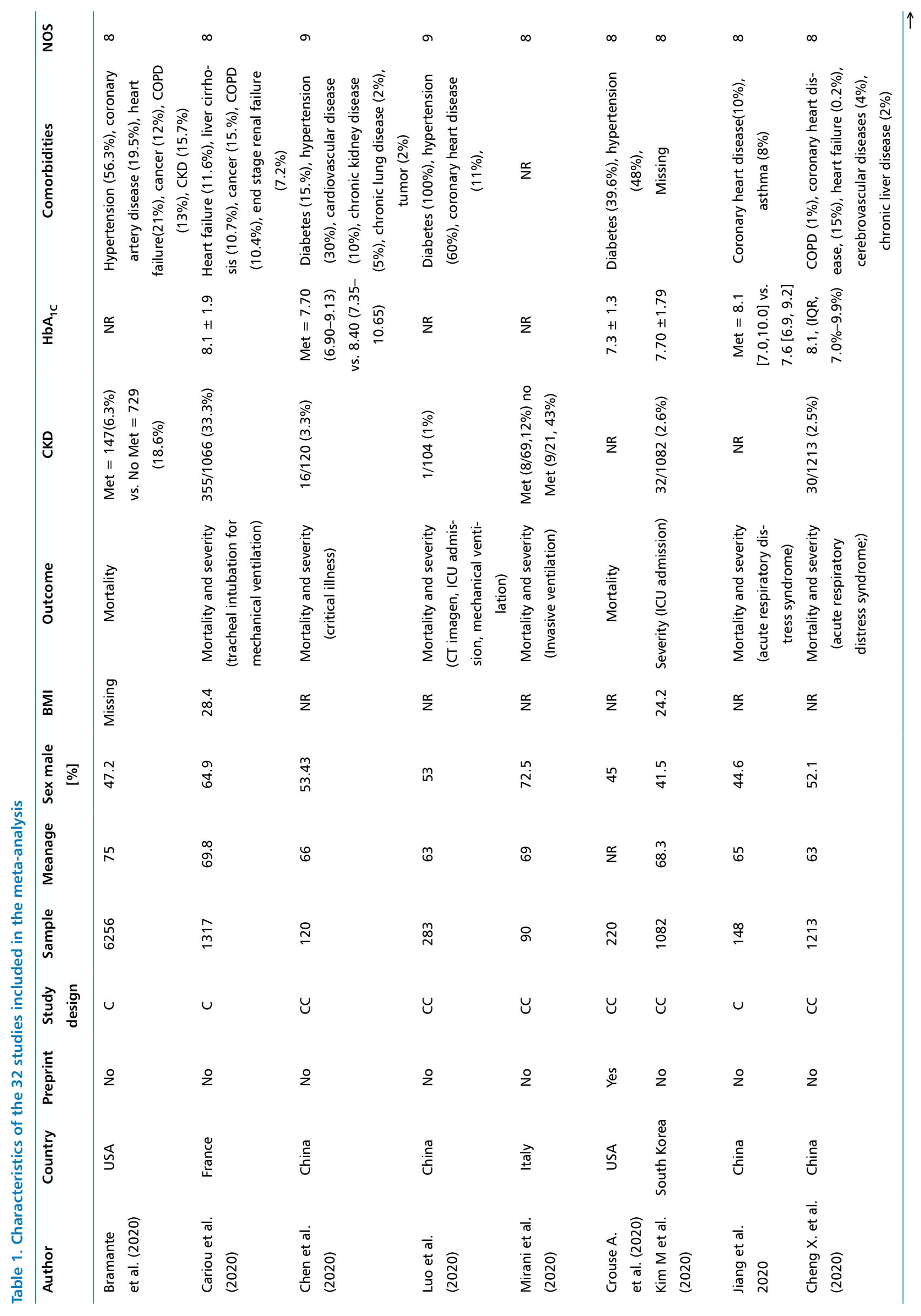




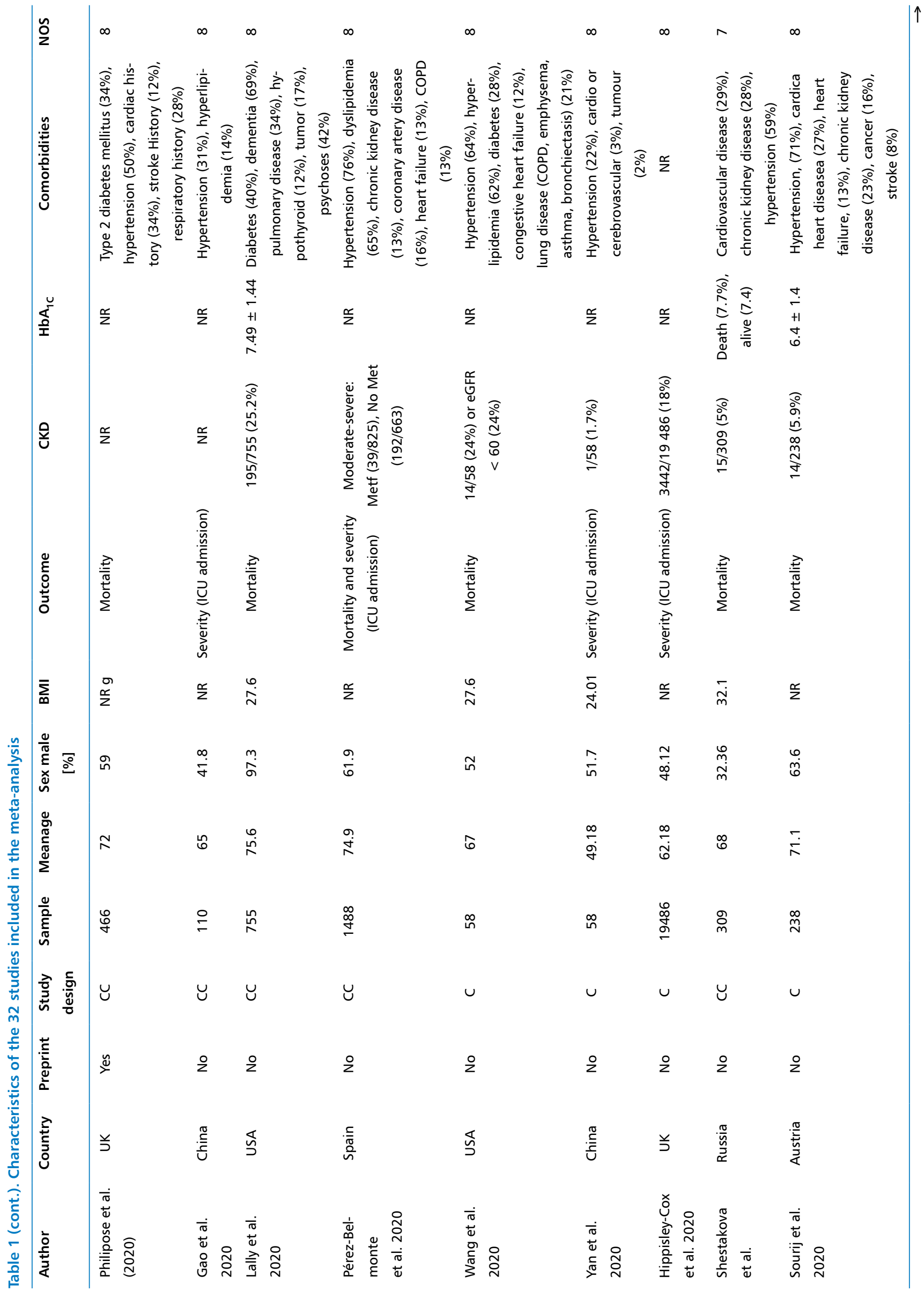




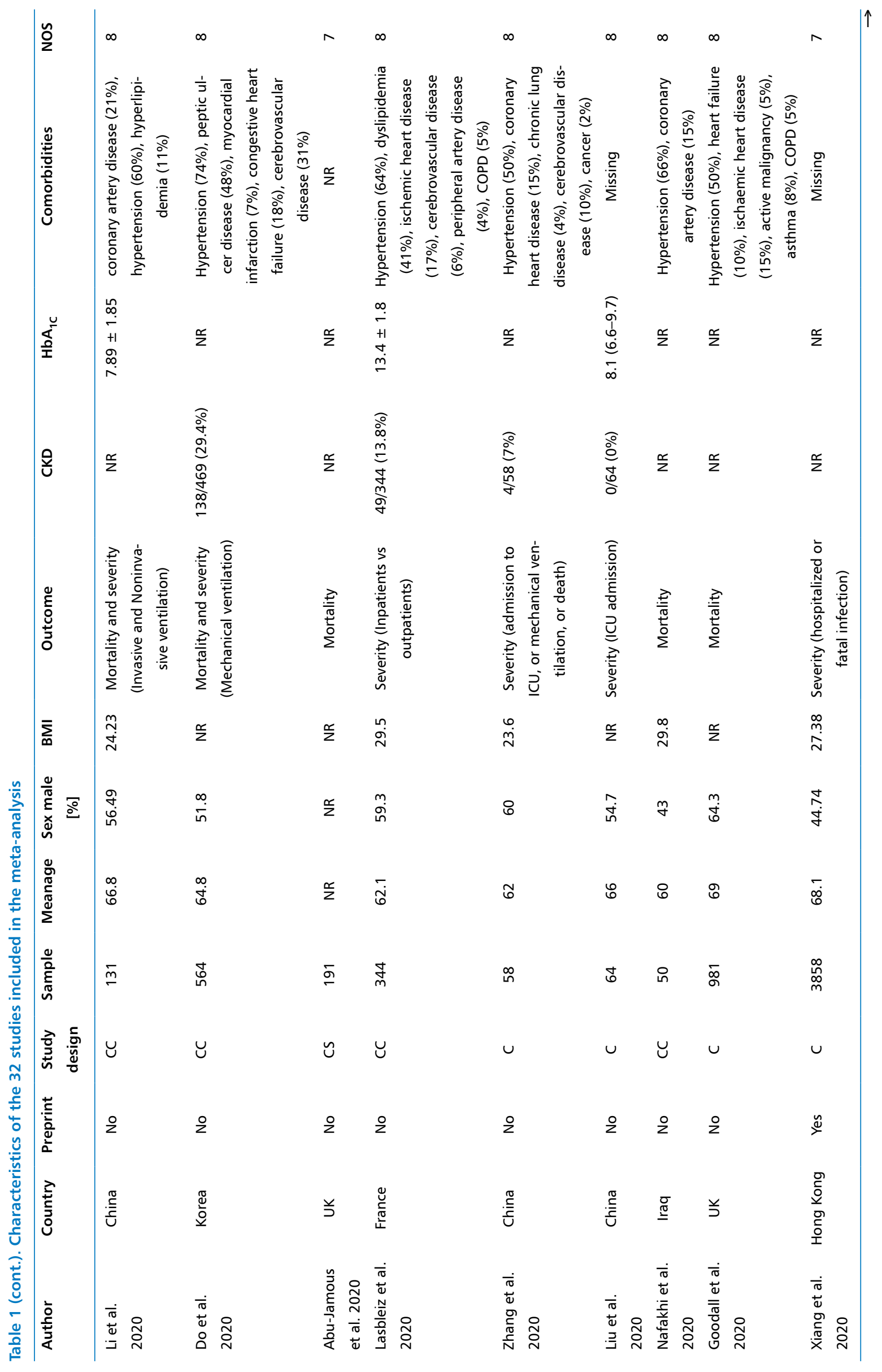




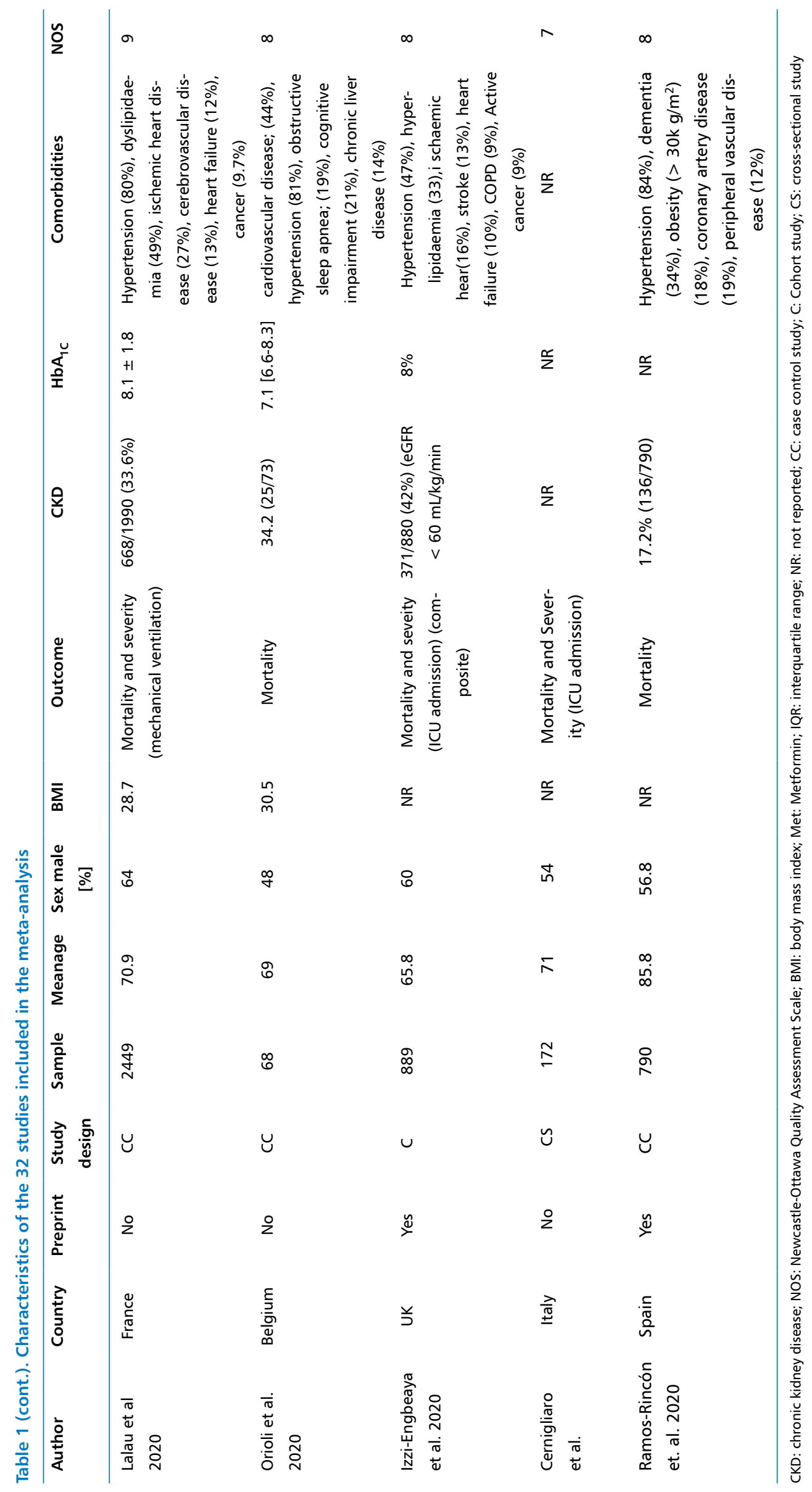




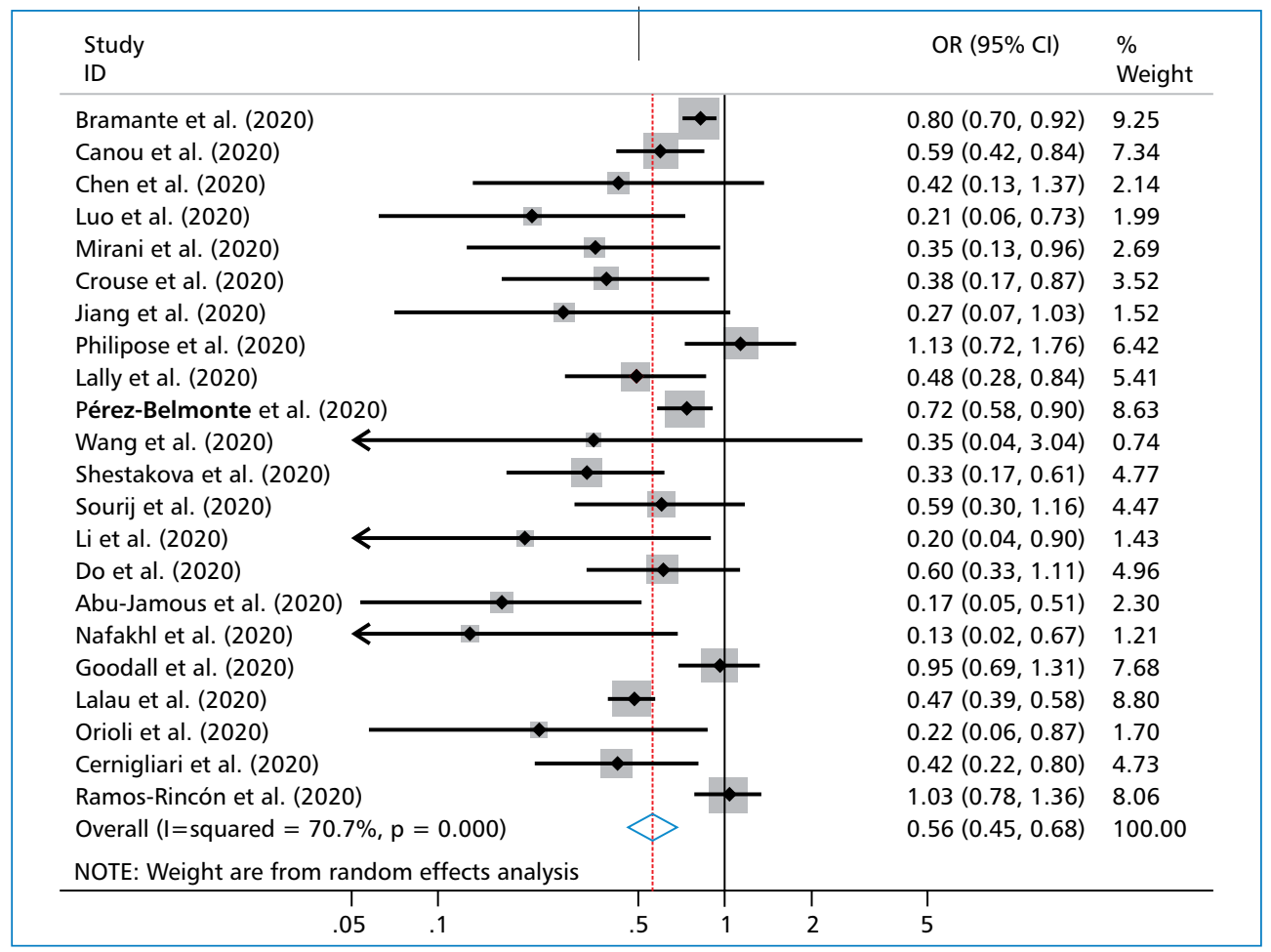

Figure 2. Forest plot of the Metformin and risk of mortality in SARS-CoV-2 infection. Analysis model: random effect. OR: odds ratio; $\mathrm{Cl}$ : confidence interval

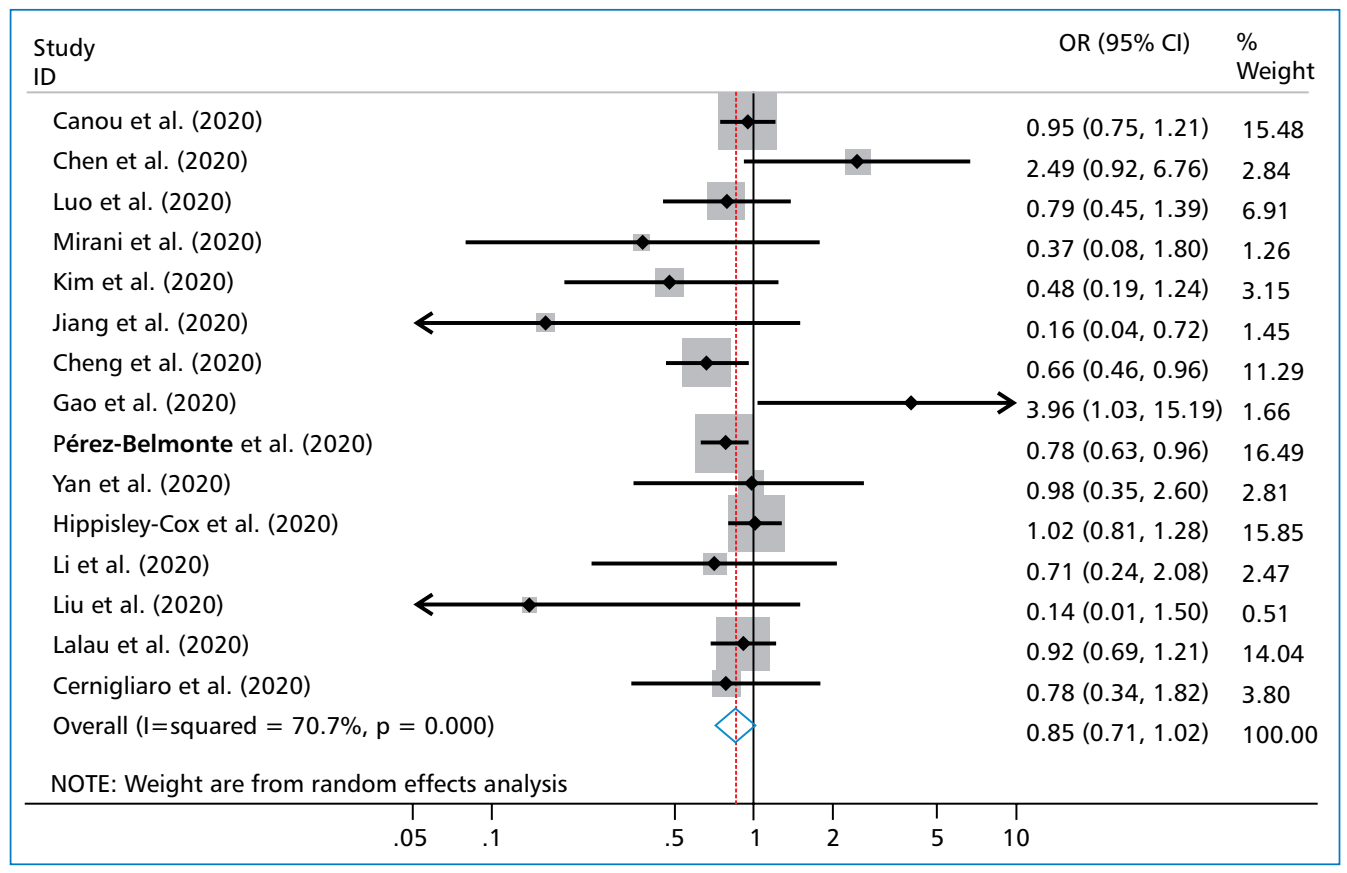

Figure 3. Forest plot of the Metformin and risk of severity in SARS-CoV-2 infection. Analysis model: random effect. OR: odds ratio; $\mathrm{Cl}$ : confidence interval

Interleukin-6 (IL-6) levels

Only 2 studies measured the serum concentration of IL-2 in patients with or without metformin [16, 30], and both reported significantly lower IL-6 levels in the group on metformin. 
Table 2. Association between use of Metformin and mortality and severity of SARS-CoV-2 infection - summary of subgroup analyses

\begin{tabular}{lccc}
\hline Subgroup & Studies $(\mathbf{n})$ & Adjusted OR $(95 \% \mathrm{Cl})$ & $\mathbf{P}$ \\
\hline $\begin{array}{l}\text { Age } \\
\text { Mortality* }\end{array}$ & & & \\
$\quad<70$ & 12 & $0.43(0.30-0.61)$ & $<0.001$ \\
$\quad \geq 70$ & 8 & $0.69(0.55-0.88)$ & 0.002 \\
$\begin{array}{c}\text { Severity } \\
\quad<70\end{array}$ & 12 & $0.84(0.64-1.11)$ & 0.221 \\
$\quad \geq 70$ & 3 & $0.83(0.70-0.97)$ & 0.023 \\
BMI & & & \\
Mortality & & & \\
$<30$ & 6 & $0.49(0.41-0.58)$ & $<0.001$ \\
$\quad \geq 30$ & 2 & $0.30(0.17-0.54)$ & $<0.001$ \\
Severity & & & \\
$\quad<30$ & 5 & $0.91(0.77-1.08)$ & 0.291 \\
$\geq 30$ & 0 & & \\
\hline
\end{tabular}

\section{Discussion}

The present study found that the previous use of metformin in patients with type 2 diabetes is associated with lower risk of mortality from SARS-CoV-2 infection but not with disease severity. However, it should be noted that this association does not imply causality. In the subgroup analysis, we found a decrease in the risk of mortality and severity in those over 70 years of age. Additionally, some studies found that previous use of metformin in diabetic patients could be related to lower levels of IL-6 during COVID-19 infection.

Prior to this study, four meta-analytic studies were published with similar findings, although with fewer studies and without severity data [46-49]. On the other hand, before the COVID-19 pandemic, Liang et al. [50] published a meta-analytical study that found that the use of metformin prior to hospitalization for septic shock may reduce mortality in diabetic patients.

Using data from the Coronavirus SARS-CoV-2 and Diabetes Outcomes (CORONADO) study, Lalau et al. [27] found that metformin was associated with a reduction in a composite endpoint (tracheal intubation for mechanical ventilation and/or death), and death by day 28, but linked to increased severity on admission regarding clinical, radiological, and biological features, compared with metformin non-users. The most likely explanation for this apparently discordant finding is that hospitalized patients who use metformin tend to be more multimorbid at baseline, rather than develop a more severe illness due to taking metformin. However, a hypothesis was proposed that the time lag between the onset of COVID-19 symptoms and hospital admis- sion was significantly longer in metformin users, and the rate of dyspnoea, a major severity criterion, was not more frequent in metformin users [27].

In the subgroup analysis, we found that metformin users had decreased risk of mortality and severity in patients with an age equal to or older than 70 years; this finding could be interesting because according to a recent meta-analyzes on 59 studies showed that patients aged 70 and above have a higher risk for COVID-19 infection, severe disease, ICU admission and death [51]. The probable mechanism by which metformin reduces mortality and severity in patients older than 70 years would be through its action at the level of mitochondrial function. It is known that decline in mitochondrial function occurs with aging and may increase mortality; on the other hand, in the pathophysiology of SARS-CoV-2 infection there is the hypothesis that mitochondrial function is compromised, specifically the complex interaction of innate immune function, viral replication, hyperinflammatory state, and HIF- $\alpha$ / sirtuin pathways (hypoxia-inducible transcription factors, HIF) [52]. Currently there is enormous interest in drugs called "inflammaging or geroprotectors", so called because they are molecules which can target chronic inflammation associated with aging, obesity, and metabolic syndrome [53]. One of these inflammaging drugs, or geroprotectors, is metformin, because it activates 5'AMP-activated protein kinase (AMPK) and inhibits the mTOR pathway, may improve metabolic derangements, improve mitochondrial function, and decrease cytokine production [54]. Recently Bharath et al. [55] demonstrated in vitro that metformin improves autophagy and mitochondria in parallel to decrease inflammaging. The findings of the present study regarding a probable protective effect in the male sex require more studies, because the included studies did not report the respective analysis separately by gender, and the division between studies with a male or female predominance may be debatable. However, these results are published to be taken into account in the design of future studies.

At the biological level, there could be possible mechanisms associated with metformin-associated antiviral, immunomodulatory and preventive activity for acute lung injury. In this regard, the relationship between glucose metabolism and viral replication have, in the past few years, started to be the object of thorough investigation, starting from HIV-1 [56, 57]. The antiviral activity of metformin has been demonstrated in dengue virus infection, by restoring AMPK activity in early stages of infection [58], in animal models with Coxsackievirus B3 (CVB3) infection [59], and Kaposi sarcoma herpesvirus [60]. It has been postulated that 
the anti-COVID-19 activity of metformin may be due to interference in the interaction of the ACE2 receptor and SARS-CoV-2, through its action on AMPK [7, 61]. At the level of human endothelial cells, AMPK phosphorylates ACE2 Ser680 and increases ACE2 expression by enhancing its stability. Metformin also enhances the phosphorylation and expression of ACE2 [28]. Phosphorylation produces a conformational and functional ACE2 receptor and decreases the binding of SARS-CoV-2, thus interfering with the entry of the virus into the human cell $[7,61]$. There is the hypothesis that Metformin could negatively alter endocytosis, maturation of endosomes, and transport of virions to the replication site [62], producing an endosomal alkaline environment, due to its direct action on the eNHEs ( $\mathrm{Na}+/ \mathrm{H}+$ exchangers) and/or the V-ATPase, two membrane compartments for the maintenance and regulation of endosomal acidic $\mathrm{pH}$ [63-65]. This mechanism would thus be similar to that of a widely studied investigational anti-SARS-CoV-2 agent, i.e. hydroxychloroquine, which however gave controversial results in vivo $[66,67]$.

Metformin may have immunomodulatory activity because it reduces the production of pro-inflammatory cytokines using macrophages, causes the formation of neutrophil extracellular traps (NETs) and inhibits the production of cytokines from pathogenic Th1 and Th17 cells; therefore, it could potentially suppress the cytokine storm produced by severe COVID-19 [68]. Experimental studies in animal models have shown that metformin has an action against lung injury [69-72]. A recent study using bovine pulmonary artery endothelial cells (BPAEC), showed that metformin enhanced the vascular barrier integrity, since it produces an increase in the transendothelial resistance of endothelial monolayers [73]. Additionally, metformin may attenuate lung injury caused by the high pressure of mechanical ventilation [74].

Two studies included in this meta-analysis found significantly lower levels of IL- 6 in diabetic patients with COVID-19 taking metformin compared to those who did not use it $[16,30]$. In this regard, before the COVID-19 pandemic, it was known that multiple myeloma patients treated with metformin had significantly lower levels of IL-6R expression and promoted apoptosis of myeloma cells [75]. The use of metformin in patients with polycystic ovary syndrome reduces serum levels of IL-6 and improves chronic inflammation [76]. Metformin can also reduce IL- 6 secretion by alveolar macrophages and reduce pulmonary thrombosis in mice [77]. Additionally, metformin can inhibit the IL-6 signaling pathway, thus overcoming the acquired resistance of lung cancer to epidermal growth factor receptor tyrosine kinase inhibitors [78]. There is, therefore, increasing interest in metformin as a potential therapeutic agent in COVID-19 infection [79].

Discontinuation of metformin has been recommended in patients with severe COVID-19 infection due to the potential risk of lactic acidosis [80]. However, in a study that included 1212 hospitalized patients with COVID-19 and pre-existing diabetes, Cheng et al. [18] found that metformin was associated with the incidence of acidosis, but not with an increase in mortality associated with COVID-19. On the contrary, metformin was associated with a significant decrease in heart failure and inflammation, but acidosis and kidney function should be carefully monitored in individuals with severe COVID-19 [18]. One study reported that $29 \%$ of patients hospitalized for COVID-19 continued to take metformin and lactic acidosis was not reported[81]. In clinical practice, metformin is generally suspended immediately after the patient is admitted in a severe state, to avoid lactic acidosis. It is possible that metformin has an effect after having been suspended, in this regard it is known that it appears to accumulate in erythrocytes, and after its suspension it remains detectable in erythrocytes up to 48 hours [82], so it takes nearly one week for total elimination of metformin from the body [83].

The present study has limitations derived from the design of the included studies, which are observational and some were preprints $(4 / 32)$ and not clinical trials. Most of the included observational studies were retrospective cohorts and potential selection bias of patients is an indisputable concern. On the other hand, in the interpretation of the analysis of their groups, caution should be taken because few studies reported data on BMI.

In conclusion the present study found that the previous use of metformin in patients with type 2 diabetes is associated with a lower risk of mortality from SARS-CoV-2 infection, but not severity. This association does not imply causation and further research is required to clarify potential mechanisms.

\section{Conflict of interest \\ None.}

\section{REFERENCES}

1. Amin S, Lux A, O'Callaghan F. The journey of metformin from glycaemic control to mTOR inhibition and the suppression of tumour growth. Br J Clin Pharmacol. 2019; 85(1): 37-46, doi: 10.1111/bcp.13780, indexed in Pubmed: 30290005.

2. Rena G, Hardie DG, Pearson ER. The mechanisms of action of metformin. Diabetologia. 2017; 60(9): 1577-1585, doi: 10.1007/ s00125-017-4342-z, indexed in Pubmed: 28776086.

3. Thomas I, Gregg B. Metformin; a review of its history and future: from lilac to longevity. Pediatr Diabetes. 2017; 18(1): 10-16, doi: 10.1111/pedi.12473, indexed in Pubmed: 28052534. 
4. Davies MJ, D'Alessio DA, Fradkin J, et al. Management of hyperglycaemia in type 2 diabetes, 2018. A consensus report by the American Diabetes Association (ADA) and the European Association for the Study of Diabetes (EASD). Diabetologia. 2018; 61(12): 2461-2498, doi: 10.1007/s00125-018-4729-5, indexed in Pubmed: 30288571.

5. Gheblawi M, Wang K, Viveiros A, et al. Angiotensin-Converting enzyme 2: SARS-CoV-2 receptor and regulator of the renin-angiotensin system: celebrating the 20th anniversary of the discovery of ACE2. Circ Res. 2020; 126(10): 1456-1474, doi: 10.1161/ CIRCRESAHA.120.317015, indexed in Pubmed: 32264791.

6. Zhang $X$, Zheng J, Yan $Y$, et al. Angiotensin-converting enzyme 2 regulates autophagy in acute lung injury through AMPK/ mTOR signaling. Arch Biochem Biophys. 2019; 672: 108061, doi: 10.1016/j.abb.2019.07.026, indexed in Pubmed: 31356776.

7. Sharma S, Ray A, Sadasivam B. Metformin in COVID-19: A possible role beyond diabetes. Diabetes Res Clin Pract. 2020; 164: 108183, doi: 10.1016/j.diabres.2020.108183, indexed in Pubmed: 32360697.

8. Chen $Y, G u$ F, Guan JL. Metformin might inhibit virus through increasing insulin sensitivity. Chin Med J (Engl). 2018; 131(3): 376-377, doi: 10.4103/0366-6999.223856, indexed in Pubmed: 29363663.

9. Rangarajan S, Bone NB, Zmijewska AA, et al. Metformin reverses established lung fibrosis in a bleomycin model. Nat Med. 2018; 24(8): 1121-1127, doi: 10.1038/s41591-018-0087-6, indexed in Pubmed: 29967351

10. Moher D, Liberati A, Tetzlaff J, et al. Preferred reporting items for systematic reviews and meta-analyses: the PRISMA statement. Int J Surg. 2010; 8(5): 336-341, doi: 10.1016/j.jjsu.2010.02.007, indexed in Pubmed: 20171303.

11. Stang A. Critical evaluation of the Newcastle-Ottawa scale for the assessment of the quality of nonrandomized studies in metaanalyses. Eur J Epidemiol. 2010; 25(9): 603-605, doi: 10.1007/ s10654-010-9491-z, indexed in Pubmed: 20652370.

12. Higgins JPT, Altman DG, Gøtzsche PC, et al. The Cochrane Collaboration's tool for assessing risk of bias in randomised trials. BMJ. 2011; 343: d5928, doi: 10.1136/bmj.d5928, indexed in Pubmed: 22008217.

13. DerSimonian R, Laird N. Meta-analysis in clinical trials. Controlled Clinical Trials. 1986; 7(3): 177-188, doi: 10.1016/01972456(86)90046-2.

14. Sourij H, Aziz F, Bräuer A, et al. COVID-19 fatality prediction in people with diabetes and prediabetes using a simple score upon hospital admission. Diabetes Obes Metab. 2021; 23(2): 589-598, doi: 10.1111/dom.14256, indexed in Pubmed: 33200501.

15. Orioli L, Servais T, Belkhir L, et al. Clinical characteristics and short-term prognosis of in-patients with diabetes and COVID-19: A retrospective study from an academic center in Belgium. Diabetes Metab Syndr. 2021; 15(1): 149-157, doi: 10.1016/j. dsx.2020.12.020, indexed in Pubmed: 33352454.

16. Chen $Y$, Yang D, Yang $C$, et al. Clinical characteristics and outcomes of patients with diabetes and COVID-19 in association with glucose-lowering medication. Diabetes Care. 2020; 43(7): 13991407, doi: 10.2337/dc20-0660, indexed in Pubmed: 32409498.

17. Luo P, Qiu L, Liu Yi, et al. Metformin treatment was associated with decreased mortality in COVID-19 patients with diabetes in a retrospective analysis. Am J Trop Med Hyg. 2020; 103(1): 69-72, doi: 10.4269/ajtmh.20-0375, indexed in Pubmed: 32446312.

18. Cheng $\mathrm{Xu}$, Liu YM, Li H, et al. Metformin is associated with higher incidence of acidosis, but not mortality, in individuals with COVID-19 and pre-existing type 2 diabetes. Cell Metab. 2020; 32(4): 537-547.e3, doi: 10.1016/j.cmet.2020.08.013, indexed in Pubmed: 32861268.

19. Gao Y, Liu T, Zhong W, et al. Risk of metformin in patients with type 2 diabetes with COVID-19: a preliminary retrospective report. Clin TransI Sci. 2020; 13(6): 1055-1059, doi: 10.1111/cts.12897, indexed in Pubmed: 32955785.
20. Yan H, Valdes A, Vijay A, et al. Role of drugs used for chronic disease management on susceptibility and severity of COVID-19: a large case-control study. medRxiv. 2020, doi: 10.1101/2020.04.24.20077875.

21. Li J, Wei Qi, Li WX, et al. Metformin use in diabetes prior to hospitalization: effects on mortality in covid-19. Endocr Pract. 2020; 26(10): 1166-1172, doi: 10.4158/EP-2020-0466, indexed in Pubmed: 33471718.

22. Zhang J, Kong W, Xia $P$, et al. Impaired fasting glucose and diabetes are related to higher risks of complications and mortality among patients with coronavirus disease 2019. Front Endocrinol (Lausanne). 2020; 11: 525, doi: 10.3389/fendo.2020.00525, indexed in Pubmed: 32754119.

23. Liu Z, Bai Xi, Han X, et al. The association of diabetes and the prognosis of COVID-19 patients: A retrospective study. Diabetes Res Clin Pract. 2020; 169: 108386, doi: 10.1016/j.diabres.2020.108386, indexed in Pubmed: 32853685.

24. Chen Z, Jiang N, Liu Li, et al. Association of metformin with mortality or ARDS in patients with COVID-19 and type 2 diabetes: A retrospective cohort study. Diabetes Res Clin Pract. 2020 [Epub ahead of print]; 173: 108619, doi: 10.1016/j.diabres.2020.108619, indexed in Pubmed: 33310173.

25. Cariou B, Hadjadj S, Wargny M, et al. Phenotypic characteristics and prognosis of inpatients with COVID-19 and diabetes: the CORONADO study. Diabetologia. 2020; 63(8): 1500-1515, doi: 10.1007/s00125-020-05180-x, indexed in Pubmed: 32472191.

26. Lasbleiz A, Cariou B, Darmon $P$, et al. Phenotypic characteristics and development of a hospitalization prediction risk score for outpatients with diabetes and COVID-19: the DIABCOVID study. J Clin Med. 2020; 9(11), doi: 10.3390/jcm9113726, indexed in Pubmed: 33233575.

27. Lalau JD, Al-Salameh A, Hadjadj S, et al. Metformin use is associated with a reduced risk of mortality in patients with diabetes hospitalised for COVID-19. Diabetes Metab. 2020 [Epub ahead of print]; 47(5): 101216, doi: 10.1016/j.diabet.2020.101216, indexed in Pubmed: 33309936.

28. Xiang $Y$, Wong $K$, Hon-Cheong SO. Exploring drugs and vaccines associated with altered risks and severity of COVID-19: a UK Biobank cohort study of all ATC level-4 drug categories. medRxiv. 2020, doi: 10.1101/2020.12.05.20244426.

29. Nafakhi H, Alareedh M, Al-Buthabhak K, et al. Predictors of adverse in-hospital outcome and recovery in patients with diabetes mellitus and COVID-19 pneumonia in Iraq. Diabetes Metab Syndr. 2021; 15(1): 33-38, doi: 10.1016/j.dsx.2020.12.014, indexed in Pubmed: 33296788.

30. Mirani M, Favacchio G, Carrone F, et al. Impact of comorbidities and glycemia at admission and dipeptidyl peptidase 4 inhibitors in patients with type 2 diabetes with COVID-19: a case series from an Academic Hospital in Lombardy, Italy. Diabetes Care. 2020; 43(12): 3042-3049, doi: 10.2337/dc20-1340, indexed in Pubmed: 33023989.

31. Cernigliaro A, Allotta AV, Scondotto S. Can diabetes and its related hypoglycemic drug treatment be considered risk factors for health outcomes in COVID-19 patients? The results of a study in the population residing in Sicily Region (Southern Italy). Epidemiol Prev. 2020; 44(5-6 Suppl 2): 315-322, doi: 10.19191/EP20.5-6. S2.132, indexed in Pubmed: 33412824.

32. Shestakova MV, Vikulova OK, Isakov M , et al. Diabetes and COVID-19: analysis of the clinical outcomes according to the data of the russian diabetes registry. Probl Endokrinol (Mosk). 2020; 66(1): 35-46, doi: 10.14341/probl12458, indexed in Pubmed: 33351311.

33. Kim MiK, Jeon JH, Kim SW, et al. The clinical characteristics and outcomes of patients with moderate-to-severe coronavirus disease 2019 infection and diabetes in Daegu, South Korea. Diabetes Metab J. 2020; 44(4): 602-613, doi: 10.4093/dmj.2020.0146, indexed in Pubmed: 32794386.

34. Do JY, Kim SW, Park JW, et al. Is there an association between metformin use and clinical outcomes in diabetes patients with COVID-19? 
Diabetes Metab. 2020 [Epub ahead of print]: 101208, doi: 10.1016/j.diabet.2020.10.006, indexed in Pubmed: 33160030.

35. Pérez-Belmonte LM, Torres-Peña JD, López-Carmona MD, et al. Mortality and other adverse outcomes in patients with type 2 diabetes mellitus admitted for COVID-19 in association with glucose-lowering drugs: a nationwide cohort study. BMC Med. 2020; 18(1): 359, doi: 10.1186/s12916-020-01832-2, indexed in Pubmed: 33190637.

36. Ramos-Rincón J, Pérez-Belmonte L, Carrasco-Sánchez F, et al. Association between prior cardiometabolic therapy and in-hospital mortality in very old patients with type 2 diabetes mellitus hospitalized due to COVID-19. A nationwide observational study in Spain. , doi: 10.21203/rs.3.rs-133358/v1

37. Philipose Z, Smati N, Wong C, et al. Obesity, old age and frailty are the true risk factors for COVID-19 mortality and not chronic disease or ethnicity in Croydon. , doi: 10.1101/2020.08.12.20156257.

38. Abu-Jamous B, Anisimovich A, Baxter J, et al. Associations of comorbidities and medications with COVID-19 outcome: A retrospective analysis of real-world evidence data. , doi: 10.1101/2020.08.20.20174169.

39. Goodall JW, Reed TAN, Ardissino M, et al. Risk factors for severe disease in patients admitted with COVID-19 to a hospital in London, England: a retrospective cohort study. Epidemiol Infect. 2020; 148: e251, doi: 10.1017/S0950268820002472, indexed in Pubmed: 33046155.

40. Izzi-Engbeaya C, Distaso W, Amin A, et al. Severe COVID-19 and diabetes - a retrospective cohort study from three london teaching hospitals. medRxiv. 2020, doi: 10.1101/2020.08.07.20160275.

41. Hippisley-Cox J, Young D, Coupland C, et al. Risk of severe COVID-19 disease with ACE inhibitors and angiotensin receptor blockers: cohort study including 8.3 million people. Heart. 2020; 106(19): 1503-1511, doi: 10.1136/heartjnl-2020-317393, indexed in Pubmed: 32737124.

42. Wang Bo, Van Oekelen O, Mouhieddine $\mathrm{TH}$, et al. A tertiary center experience of multiple myeloma patients with COVID-19: lessons learned and the path forward. J Hematol Oncol. 2020; 13(1): 94, doi: 10.1186/s13045-020-00934-x, indexed in Pubmed: 32664919.

43. Lally MA, Tsoukas $P$, Halladay CW, et al. Metformin is associated with decreased 30-day mortality among nursing home residents infected with SARS-CoV-2. J Am Med Dir Assoc. 2021; 22(1): 193-198, doi: 10.1016/j.jamda.2020.10.031, indexed in Pubmed: 33232684.

44. Bramante C, Ingraham N, Murray T, et al. Metformin and risk of mortality in patients hospitalised with COVID-19: a retrospective cohort analysis. The Lancet Healthy Longevity. 2021; 2(1): e34-e41, doi: 10.1016/s2666-7568(20)30033-7.

45. Crouse AB, Grimes T, Li P, et al. Metformin use is associated with reduced mortality in a diverse population with COVID-19 and diabetes. Front Endocrinol (Lausanne). 2020; 11: 600439, doi: 10.3389/fendo.2020.600439, indexed in Pubmed: 33519709.

46. Hariyanto TI, Kurniawan A. Metformin use is associated with reduced mortality rate from coronavirus disease 2019 (COVID-19) infection. Obes Med. 2020; 19: 100290, doi: 10.1016/j. obmed.2020.100290, indexed in Pubmed: 32844132.

47. Scheen AJ. Metformin and COVID-19: From cellular mechanisms to reduced mortality. Diabetes Metab. 2020; 46(6): 423-426, doi: 10.1016/j.diabet.2020.07.006, indexed in Pubmed: 32750451.

48. Lukito AA, Pranata R, Henrina J, et al. The effect of metformin consumption on mortality in hospitalized COVID-19 patients: a systematic review and meta-analysis. Diabetes Metab Syndr. 2020; 14(6): 2177-2183, doi: 10.1016/j.dsx.2020.11.006, indexed in Pubmed: 33395778.

49. Schlesinger S, Neuenschwander M, Lang A, et al. Risk phenotypes of diabetes and association with COVID-19 severity and death - a living systematic review and meta-analysis. SSRN Electronic Journal. , doi: 10.2139/ssrn.3730026.

50. Liang $H$, Ding $X$, Li L, et al. Association of preadmission metformin use and mortality in patients with sepsis and diabetes mellitus: a systematic review and meta-analysis of cohort studies. Crit Care. 2019; 23(1): 50, doi: 10.1186/s13054-019-2346-4, indexed in Pubmed: 30777119.

51. Pijls BG, Jolani S, Atherley A, et al. Demographic risk factors for COVID-19 infection, severity, ICU admission and death: a metaanalysis of 59 studies. BMJ Open. 2021; 11(1): e044640, doi: 10.1136/bmjopen-2020-044640, indexed in Pubmed: 33431495.

52. Shenoy S. Coronavirus (Covid-19) sepsis: revisiting mitochondrial dysfunction in pathogenesis, aging, inflammation, and mortality. Inflamm Res. 2020; 69(11): 1077-1085, doi: 10.1007/s00011020-01389-z, indexed in Pubmed: 32767095.

53. Mueller AL, McNamara MS, Sinclair DA. Why does COVID-19 disproportionately affect older people? Aging (Albany NY). 2020; 12(10): 9959-9981, doi: 10.18632/aging.103344, indexed in Pubmed: 32470948.

54. Vachharajani VT, Liu T, Brown CM, et al. SIRT1 inhibition during the hypoinflammatory phenotype of sepsis enhances immunity and improves outcome. J Leukoc Biol. 2014; 96(5): 785-796, doi: 10.1189/jlb.3MA0114-034RR, indexed in Pubmed: 25001863.

55. Bharath LP, Agrawal M, McCambridge G, et al. Metformin enhances autophagy and normalizes mitochondrial function to alleviate aging-associated inflammation. Cell Metab. 2020; 32(1): 44-55.e6, doi: 10.1016/j.cmet.2020.04.015, indexed in Pubmed: 32402267.

56. Shytaj I, Procopio F, Tarek M, et al. Glycolysis downregulation is a hallmark of HIV-1 latency and sensitizes infected cells to oxidative stress. bioRxiv. 2020, doi: 10.1101/2020.12.30.424810.

57. Valle-Casuso JC, Angin M, Volant S, et al. Cellular metabolism is a major determinant of HIV-1 reservoir seeding in CD4 $t$ cells and offers an opportunity to tackle infection. Cell Metab. 2019; 29(3): 611-626.e5, doi: 10.1016/j.cmet.2018.11.015, indexed in Pubmed: 30581119.

58. Soto-Acosta R, Bautista-Carbajal P, Cervantes-Salazar M, et al. DENV up-regulates the HMG-CoA reductase activity through the impairment of AMPK phosphorylation: A potential antiviral target. PLoS Pathog. 2017; 13(4): e1006257, doi: 10.1371/journal. ppat.1006257, indexed in Pubmed: 28384260.

59. Xie W, Wang L, Dai Q, et al. Activation of AMPK restricts coxsackievirus B3 replication by inhibiting lipid accumulation. J Mol Cell Cardiol. 2015; 85: 155-167, doi: 10.1016/j.yjmcc.2015.05.021, indexed in Pubmed: 26055448.

60. Cheng F, He M, Jung JU, et al. Suppression of Kaposi's sarcomaassociated herpesvirus infection and replication by $5^{\prime}$-ampactivated protein kinase. J Virol. 2016; 90(14): 6515-6525, doi: 10.1128/JVI.00624-16, indexed in Pubmed: 27147746.

61. Plattner F, Bibb J. Serine and threonine phosphorylation. Basic Neurochemistry. 2012: 467-492, doi: 10.1016/b978-0-12374947-5.00025-0.

62. Esam Z. A proposed mechanism for the possible therapeutic potential of Metformin in COVID-19. Diabetes Res Clin Pract. 2020; 167: 108282, doi: 10.1016/j.diabres.2020.108282, indexed in Pubmed: 32592841.

63. Kim J, You YJ. Regulation of organelle function by metformin. IUBMB Life. 2017; 69(7): 459-469, doi: 10.1002/iub.1633, indexed in Pubmed: 28444922.

64. Zhang CS, Li M, Ma T, et al. Metformin activates AMPK through the lysosomal pathway. Cell Metab. 2016; 24(4): 521-522, doi: 10.1016/j.cmet.2016.09.003, indexed in Pubmed: 27732831.

65. Glossmann HH, Lutz OMD. Metformin and aging: a review. Gerontology. 2019; 65(6): 581-590, doi: 10.1159/000502257, indexed in Pubmed: 31522175.

66. Oscanoa TJ, Romero-Ortuno R, Carvajal A, et al. A pharmacological perspective of chloroquine in SARS-CoV-2 infection: An old drug for the fight against a new coronavirus? Int J Antimicrob Agents. 2020; 56(3): 106078, doi: 10.1016/j.ijantimicag.2020.106078, indexed in Pubmed: 32629115.

67. Oscanoa TJ, Vidal X, Kanters JK, et al. Frequency of long QT in patients with sars-cov-2 infection treated with hydroxychloroquine: a meta-analysis. Int J Antimicrob Agents. 2020; 56(6): 
106212, doi: 10.1016/j.ijantimicag.2020.106212, indexed in Pubmed: 33164789.

68. Chen X, Guo H, Qiu Li, et al. Immunomodulatory and antiviral activity of metformin and its potential implications in treating coronavirus disease 2019 and lung injury. Front Immunol. 2020; 11: 2056, doi: 10.3389/fimmu.2020.02056, indexed in Pubmed: 32973814.

69. Zhang $X$, Shang F, Hui L, et al. The alleviative effects of metformin for lipopolysaccharide-induced acute lung injury rat model and its underlying mechanism. Saudi Pharm J. 2017; 25(4): 666-670, doi: 10.1016/j.jsps.2017.05.001, indexed in Pubmed: 28579909.

70. Wu K, Tian R, Huang J, et al. Metformin alleviated endotoxemiainduced acute lung injury via restoring AMPK-dependent suppression of mTOR. Chem Biol Interact. 2018; 291: 1-6, doi: 10.1016/j. cbi.2018.05.018, indexed in Pubmed: 29859833.

71. Wu L, Cen $Y$, Feng $M$, et al. Metformin activates the protective effects of the AMPK pathway in acute lung injury caused by paraquat poisoning. Oxid Med Cell Longev. 2019; 2019: 1709718, doi: 10.1155/2019/1709718, indexed in Pubmed: 31781324.

72. Zmijewski JW, Lorne E, Zhao X, et al. Mitochondrial respiratory complex I regulates neutrophil activation and severity of lung injury. Am J Respir Crit Care Med. 2008; 178(2): 168-179, doi: 10.1164/ rccm.200710-16020C, indexed in Pubmed: 18436790.

73. Uddin MA, Akhter MS, Kubra KT, et al. Metformin in acute respiratory distress syndrome: An opinion. Exp Gerontol. 2021; 145: 111197, doi: 10.1016/j.exger.2020.111197, indexed in Pubmed: 33310152

74. Tsaknis G, Siempos II, Kopterides $P$, et al. Metformin attenuates ventilator-induced lung injury. Crit Care. 2012; 16(4): R134, doi: 10.1186/cc11439, indexed in Pubmed: 22827994.

75. Mishra AK, Dingli D. Metformin inhibits IL- 6 signaling by decreasing IL-6R expression on multiple myeloma cells. Leukemia. 2019; 33(11): 2695-2709, doi: 10.1038/s41375-019-0470-4, indexed in Pubmed: 30988378.
76. Xu X, Du C, Zheng Q, et al. Effect of metformin on serum interleukin-6 levels in polycystic ovary syndrome: a systematic review. BMC Womens Health. 2014; 14: 93, doi: 10.1186/1472-6874-1493, indexed in Pubmed: 25096410.

77. Soberanes S, Misharin AV, Jairaman A, et al. Metformin targets mitochondrial electron transport to reduce air-pollution-induced thrombosis. Cell Metab. 2019; 29(2): 335-347.e5, doi: 10.1016/j. cmet.2018.09.019, indexed in Pubmed: 30318339.

78. Li Li, Han R, Xiao H, et al. Metformin sensitizes EGFR-TKI-resistant human lung cancer cells in vitro and in vivo through inhibition of IL-6 signaling and EMT reversal. Clin Cancer Res. 2014; 20(10): 2714-2726, doi: 10.1158/1078-0432.CCR-13-2613, indexed in Pubmed: 24644001.

79. Pan Y, Han R, He Y. Metformin: one of the possible options to reduce the mortality of severe coronavirus disease 2019? Zhonghua Wei Zhong Bing Ji Jiu Yi Xue. 2020; 32(9): 1131-1134, doi: 10.3760/cma.j.cn121430-20200514-00662, indexed in Pubmed: 33081905.

80. Bornstein S, Rubino F, Khunti K, et al. Practical recommendations for the management of diabetes in patients with COVID-19. The Lancet Diabetes \& Endocrinology. 2020; 8(6): 546-550, doi: 10.1016/s2213-8587(20)30152-2.

81. Akter F, Mannan A, Mehedi H, et al. Clinical manifestations along with biochemical and psychological outcomes of COVID-19 cases in diabetic individuals in Bangladesh. , doi: 10.1101/2020.09.24.20200790.

82. Robert F, Fendri S, Hary L, et al. Kinetics of plasma and erythrocyte metformin after acute administration in healthy subjects. Diabetes Metab. 2003; 29(3): 279-283, doi: 10.1016/s12623636(07)70037-x, indexed in Pubmed: 12909816.

83. Lalau JD, Lacroix C. Measurement of metformin concentration in erythrocytes: clinical implications. Diabetes Obes Metab. 2003; 5(2): 93-98, doi: 10.1046/j.1463-1326.2003.00241.x, indexed in Pubmed: 12630933.

\section{Appendix 1}

\section{MEDLINE search strategy}

We searched the NCBI and Medline databases for potentially eligible records.

The search terms were as follows:

\#1: SARS-CoV-2 OR COVID-19

\#2: metformin OR biguanides

\#3: mortality OR severity

\#4: \#2 OR \#3

\#5: \#1 AND \#4 